\title{
ATIVISMo DigitAl E NOVOS SUJEITOS DOS DISCURSOS: A NARRATIVA DO MOVIMENTO “OCUPA ESCOLA" NO FACEBOOK
}

\author{
Danielle Miranda
}

\begin{abstract}
RESUMO
A partir do movimento occupy de estudantes secundaristas brasileiros (2015-2017), buscamos observar como o discurso enunciado da perspectiva dos manifestantes na rede acumulam, transmitem e movimentam sentidos, em uma configuração complexa que subverte a lógica de enunciados veiculados sobre movimentos sociais na mídia tradicional do Brasil. Adotamos o conceito de multidão (Negri, 2002, 2003, 2004, 2014; Hardt \& Negri, 2005) para investigar de que modos estão sendo manifestadas as expressões identitárias do movimento "Ocupa Escola" nos seus perfis do Facebook pelos próprios sujeitos desse movimento. Em uma análise qualitativa de fan pages do Facebook, tomando como critério a escolha dos perfis mais seguidos e mais partilhados pelos estudantes manifestantes, entre as regularidades percebidas na análise, destacamos com mais intensidades os temas da horizontalidade, autonomia e de um movimento sem liderança; a abertura à diversidade e a insistente necessidade em reafirmar o cuidado público com a escola. Nessa composição, não há categorias isoladas. As temáticas se articulam e os procedimentos estratégicos de expressão identitária do movimento operam em conexão. Discutimos ainda alguns desses procedimentos que a análise permitiu identificar.
\end{abstract}

\section{Palavras-chave}

"Ocupa Escola"; ocupações secundaristas; occupy; ativismo digital; Facebook; manifestações identitárias

\begin{abstract}
Based on the Brazilian secondary student's movement, known as occupy (2015-2017), we intend to observe how the discourse enunciated from the perspective of students on social media accumulate and transmit movements, in a complex configuration that subverts the logic of statements transmitted on social movements in Brazil's traditional media. We have adopted the concept of the multitude (Negri, 2002, 2003, 2004, 2014; Hardt \& Negri, 2015) to investigate, in which ways, students of the movement "Ocupa Escola" manifest identity expressions on their Facebook profiles. In a qualitative analysis of Facebook fan pages that use the selection of the most followed and shared Facebook profiles as a criterion, we highlight the themes of horizontality, autonomy and of a movement without leadership; the openness to diversity and the insistent need to reaffirm governmental care with public schools. In this composition, there are no isolated categories. The themes are articulated and the strategical procedures of identity expressions of the movement operate in connection. Finally, we discuss some of the aforementioned procedures that our analysis allowed us to identify.
\end{abstract}

\section{Palavras-chave}

"Ocupa Escola"; secondary occupations; occupy; digital activism; Facebook; identity demonstrations 


\section{INTRODUÇÃo: O MOVIMENTO “OCUPA ESCOLA" ENQUANTO OBJETO PENSADO À LUZ Do SENTIDO POLÍ́TICO DAS MULTIDÕES}

O movimento das ocupações de estudantes secundaristas e universitários brasileiros, chamado de movimento "Ocupa Escola"; "Ocupações Secundaristas" ou "Primavera Secundarista" - cujo contexto de surgimento será melhor abordado na seção seguinte, pode e deve ser compreendido no contexto de emergência de novos modos de produção e distribuição de narrativas que se dá em nossa contemporaneidade. Enquanto potencialidade política de transformação cultural, social, partimos da percepção da riqueza informacional contida nos enunciados expressos pelas ocupações secundaristas no Brasil e a forma como fomos constatando o quanto suas manifestações nas redes digitais acumulam, transmitem e movimentam sentidos, em uma configuração complexa que se associa a diferentes campos ativistas, políticos, educacionais, culturais e sociais. Além disso, apresentam novas possibilidades comunicacionais, à medida que a narrativa do movimento "Ocupa Escola" foi sendo construída majoritariamente da perspectiva de seus manifestantes, subvertendo alguns dos enunciados veiculados sobre ele na mídia tradicional do Brasil.

Ao olhar para as comunicações produzidas na rede pelos próprios secundaristas, chamou nossa atenção a diversidade e a multiplicidade dos "eus" comunicados, assim como as potencialidades decorrentes disso. Conforme sintetiza Malini (2016)' ', as ocupações dos estudantes são compostas por diferentes identidades coletivas: "são, ao mesmo tempo, movimentos sociais (feminismo, estudantil, ambiental, de luta pelo direito à cidade, etc.) e movimentos culturais (o hip hop, o funk, slow food, etc.)", o que reconfigura uma "mentalidade política até então não vivenciada nos fechados currículos escolares" (Malini, 2016, s.p.). Tais características fizeram com que nos aproximássemos do conceito de multidão, a partir de Negri (2003, 2004, 2014), Hardt e Negri (2005), Silva, Nonino e Macedo (2016), para buscar perceber como os fluxos entre processos de singularização e de constituição identitária estão sendo expressos pelos canais comunicativos desse movimento. São os sentidos políticos do conceito de multidão que mostram-se mais produtivos para os fins desse artigo, já que a sua perspectiva abre espaço para pensarmos em singularidades não representáveis, em singularidades que mantêm sua força própria, mas dentro de uma dinâmica relacional que permite construir ao mesmo tempo a si e ao todo (Negri \& Hardt, 2005). Com isso, nosso objetivo é investigar de que modos estão sendo manifestadas as expressões identitárias do movimento "Ocupa Escola" nos seus perfis do Facebook.

A multidão, em Negri (2004), é caracterizada a partir de três condições principais: ela é uma imanência, no sentido em que se mostra como potência, como conjunto de singularidades, de multiplicidades de subjetividades em que cada indivíduo ou conjunto de indivíduos é singular e, ao mesmo tempo, o uno transforma-se em múltiplo (Negri, 2004, p. 15); é um conceito de classe, de uma classe não operária, mas que constitui "a cooperação social para a produção" (Negri, 2004, p. 15); e também um conceito de potência, o mais importante para nós, enquanto conjunto que supera a massa, capaz de

\footnotetext{
' Retirado de https://medium.com/@fabiomalini/o-ecossistema-sócio-midiático-do-ocupatudo-cf589ao781af\#.bfovoi6i7
} 
desenvolvimento autônomo e independente e de romper com a ideia de uma "categoria passiva frente ao poder constituinte" (Negri, 2003, p. 139). A multidão, é, portanto, "uma multiplicidade que age" (Negri, 2004, p. 18). Dessa conceituação, surgem as articulações sobre as singularidades e identidades possíveis de serem encontradas na multidão.

Nossa intenção é olhar para o movimento das ocupações estudantis pela lente da multidão desde o princípio reconhecendo que a multidão não será uniforme e não se constituirá em uma unidade identitária. Queremos perceber justamente o entre ${ }^{2}$, o lugar onde as diferenças se encontram e se articulam. Buscamos, assim, perceber em que grau uma multiplicidade identitária aparece, e como se relaciona com o caráter de potência da multidão. Concordamos com Silva e colegas (2016) quando estes afirmam que um pensamento sobre a multidão não implica "a exterioridade das singularidades em relação às identidades. A identidade como um existente atualizado é apenas uma ocorrência específica da singularidade, entendida aqui como potencialidade" (Silva et al., 2016, p. 182) ${ }^{3}$. A definição de singularidade passa pelos processos de singularização como um "devir diferencial" (Guattari \& Rolnik, 2011, p. 56), são elementos nômades, não-hierarquizados e sempre da ordem da multiplicidade (Guattari \& Rolnik, 2011). Desse modo, tomamos a multidão como uma perspectiva que impõe pensar a oposição entre a diversidade e uma uniformidade desejada, implica vislumbrar a diversidade na sua riqueza, pois é "na riqueza de suas infinitas expressões (que a multidão) revela sua força criadora" (Negri, 2002, p. 455). Trata-se, para Negri, de um modelo que rompe com a uniformidade a abraça a diversidade em sua própria consistência ontológica.

\section{"OCUPA ESCOLA": BREVE CONTEXTO DAS OCUPAÇÕES ESTUDANTIS NO BRASIL (2015 - EM CURSO)}

Seguindo a cartilha de ocupação elaborada por estudantes argentinos e chilenos, e motivados pelo agravamento brusco da precariedade de condições das escolas públicas brasileiras, os secundaristas começaram o movimento de ocupação das escolas em São Paulo em novembro de 2015 e, por diferentes motivos, tais ocupações repetiram-se pelo Brasil até dezembro de 2016. As ocupações tomaram forma não apenas no sentido local e pontual de um país cuja educação se precariza, mas também no cenário global, que tem se transformado diacronicamente de forma mais evidente desde movimentos sociais com vínculos à era digital, como a "Primavera Árabe", o Occupy Wall Street, as revoluções na Tunísia e no Egito, o movimento espanhol "15M/Indignados".

Segundo Perissé $(2011)^{4}$, autor do livro Palavras e origens, a palavra "ocupar" origina-se do latim occupare, formado pelo prefixo ob- e o verbo capere, que remetem a significados tais como: "pegar", "apanhar”, “capturar”, "apoderar-se”, "conquistar” (Perissé,

\footnotetext{
${ }_{2}^{2}$ Pensamos o sentido de "entre" a partir de Deleuze e Guattari, "entre as coisas não designa uma correlação localizável que vai de uma para outra e reciprocamente, mas uma direção perpendicular, um movimento transversal que as carrega uma e outra" (Deleuze \& Guattari, 1995, p. 37, grifo nosso).

${ }^{3}$ Retirado de http://seer.ufrgs.br/index.php/intexto/article/view/66964/39613

${ }_{4}^{4}$ Retirado de http://palavraseorigens.blogspot.pt/2011/11/quem-ocupa-se-preocupa.html
} 
2011 , s.p.). A utilização do verbo ocupar e do termo "ocupações" no Brasil, país de língua portuguesa, decorre das transformações recentes de significado associado ao termo "occupy" (\#occupy) no idioma inglês. Occupy chegou a ser escolhida a Palavra do Ano em 2011, pela American Dialect Society5. No ano seguinte, Samy Alim, diretor do Centro de Estudos de Raça, Etnia e Linguagens da Universidade de Stanford (2012a, $2012 b)^{6}$, teve textos publicados sugerindo o movimento Occupy Wall Street como principal origem dos novos significados da palavra "occupy/ocupação". Até há pouco tempo, para o pesquisador, "ocupar" significava operação militar. Hoje, ocupar é sinônimo de luta política progressista. Para Salim (2012a, 2012b), na linguagem corrente, países, exércitos, polícias, "ocupavam" territórios, praticamente sempre pela força. Para ele, colonizadores ocuparam e não "descobriram" países. Mas, hoje, "ocupar" é um termo que está associado a "denunciar injustiças, desigualdades, abusos de poder. E não se trata de apenas impor-se num espaço: hoje, ocupar significa também transformar os espaços" (Alim, 2012a).

As ocupações de escolas no Brasil surgiram quando os estudantes das escolas públicas do estado de São Paulo entenderam que a "reorganização escolar" imposta pelo governador Geraldo Alckmin (PSDB), que fecharia mais de 90 colégios e remanejaria mais de 300.000 alunos, era um abuso. Ocuparam então as escolas no final de 2015 . Em 2016, o movimento seguiu-se, reivindicando melhores condições na educação e denunciando os Projetos de Lei 44 (privatização do ensino) 7 e 190 (Escola Sem Partido) ${ }^{8}$ e, mais recentemente, contra a PEC 241, que congela gastos públicos por 20 anos na educação e saúde, afetando os mais pobres do país. Contra a PEC 241, o movimento cresceu e também as universidades públicas brasileiras aderiram ao movimento de ocupações ${ }^{9}$. Uma onda que se espalha por mimetização e contágio (Bentes, 2016) ${ }^{10}$ e que em 2016 contou com mais de 1.110 escolas, institutos e universidades ocupadas.

No caso do Brasil e do movimento realizado por estudantes, não se pode, ainda, perder de vista que o termo "ocupar" tem o sentido também de preencher. O ocupante,

\footnotetext{
${ }^{5}$ Retirado de http://www.americandialect.org/occupy-is-the-2011-word-of-the-year

${ }^{6}$ Retirado de http://www.revistaforum.com.br/2012/01/or/a-palavra-do-ano-e-occupy/e http://opinionator.blogs.nytimes. com/2011/12/21/what-if-we-occupied-language/?_r=0

7 O PL 44 - projeto de lei 044/15 - prevê que entidades privadas sem fins lucrativos possam firmar parcerias com o poder público para exercer atividades em áreas como o ensino, a saúde, a cultura e a preservação ao meio ambiente. Para isso, essas entidades poderiam receber recursos públicos e até mesmo estruturas físicas pertencentes ao Estado. A lei possui implicações diretas na privatização do ensino público. Retirado de http://www.al.rs.gov.br/

8 O projeto de lei 190/15 pretende a instituição do Programa "Escola sem Partido", cujo mote principal é "educação sem doutrinação". Um dos pontos mais controversos destes projetos reside na ideia de que os educadores e educadoras não devem discutir, nos espaços escolares, temas e conteúdos que possam contradizer as convicções morais dos pais e mães dos estudantes. Retirado de http://marcelvanhattem.com.br/wp/wp-content/uploads/2016/06/PL-190-2015-escola.pdf
}

${ }_{9}^{A}$ A PEC 241 - Proposta de Emenda à Constituição 241/16 - propõe criar um teto de congelamento de gastos públicos pelos próximos 20 anos, medida defendida pelo governo de Michel Temer, presidente interino que assumiu após o impeachment da presidente Dilma Rousself em 2016. Nas redes sociais, essa PEC é chamada pelos seus críticos de \#PECdofimdomundo, \#PECdamaldade, \#PECdamorte, entre outras críticas. Retirado de http://www.camara.gov.br/proposicoesWeb/ prop_mostrarintegra;jsessionid=279D613E05929958381B2D3EEC573B4E.proposicoesWebExterno2? codteor=1468431\&file name $=P E C+241 / 2016$

${ }^{10}$ Retirado de https://revistacult.uol.com.br/home/a-ultima-maca-do-paraiso/ 
no entanto, não é necessariamente o proprietário ou o controlador, mas é aquele que está na "posse de". Os estudantes brasileiros ocuparam territorialmente suas instituições de ensino, mas também, de outras formas, as redes digitais e pautaram, ainda que em volume desproporcionalmente pequeno em relação ao tamanho da sua organização, os média tradicionais. Nessa perspectiva, os perfis do Facebook do "Ocupa Escola" se constituíram para romper com os códigos vigentes e assim se fazer voz audível. Juntamente com seus objetivos políticos-educacionais, encontramos aqui objetivos operacionais de ordem comunicativa-estético-política que foram, sem dúvida, provocadores de ruptura e disrupção (Rosário, Silva \& Silva, 2016)" ${ }^{11}$. Passamos às próximas seções, nas quais apresentamos nosso modo de olhar para o objeto, assim como os principais resultados da análise.

\section{OBSERVAÇÕES METODOLÓGICAS}

Neste trabalho, optamos por buscar perceber as conexões, regularidades e irregularidades que aparecem nas manifestações produzidas pelos próprios estudantes secundaristas a respeito de si e do movimento do qual fazem parte. Uma das características que o movimento tomou no Brasil é que, mesmo que possuam presença bastante relevante no Twitter, é no Facebook que os estudantes secundaristas encontraram o seu canal para criar páginas oficiais para cada ocupação. Em 2016, foi possível perceber um número volumoso de páginas surgindo, à medida que o movimento crescia e cada nova escola participante produzia sua fan page.

O nosso objeto de análise serão os perfis do Facebook de ocupacões brasileiras. $\mathrm{Na}$ "era do perfil", o perfil do Facebook é um canal que "reproduz a lógica de rede, deixa claro quem se compartilha, quem se segue (...). É um rompimento com a ideia do portal, do cliente/consumidor, da relação emissão/recepção". Consideramos, assim, o perfil das redes sociais como uma "expressão pública, um lugar público que produz experiências coletivas novas"12 e que tal expressão produz dinâmicas discursivas que nos auxiliam a compreender questões identitárias envolvidas no fenômeno.

Para compor nosso corpus de forma representativa, observamos quatro fan pages do movimento. Dois grandes perfis nacionais, um perfil estadual (do Rio de Janeiro) e um perfil específico de uma escola ocupada (Escola Padre Réus, Porto Alegre). Para a seleção, acessamos os dados públicos do Labic - Laboratório de Estudos sobre Imagem e Cibercultura ${ }^{13}$ da Universidade Federal do Espírito Santo, Brasil, sobre o ecossistema midiático das ocupações estudantis para selecionar nossas fan pages a partir de critérios de impacto - páginas com maior número de seguidores ocupantes e páginas mais compartilhadas pelos secundaristas ${ }^{14}$. As páginas "Não fechem minha escola" (216.000 fãs),

\footnotetext{
"Retirado de http://seer.ufrgs.br/index.php/intexto/article/view/67924/39623

${ }^{12}$ Declarações dadas em entrevista por Fábio Malini, publicadas no vídeo de Toturra, 2016

${ }^{13}$ O site do Labic está disponível em http://www.labic.net/labic/

${ }^{14}$ Os dados aqui expostos são disponibilizados publicamente pelo Labic e obtidos através de metadados fornecidos pelo Facebook, utilização do software Adilio, produzido pelo próprio laboratório, e análise de seus pesquisadores. Retirado de http://www.labic.net/labic/
} 
"O mal educado" (83.000 fãs), "Escolas do RJ em luta" (38.00o fãs), "Jornalistas Livres" (674.00o fãs) e "Mídia Ninja" (1,2 milhões de fãs) são as fanpages mais seguidas pelos ocupas ${ }^{15}$. Complementarmente, as páginas mais compartilhadas pelos canais do movimento no Facebook são "O mal educado", "Não fechem a minha escola"16, "Escolas do Rio em Luta", "Greve Educação Estadual RJ", "Jornalistas Livres" e "Mídia Ninja"17. Assim, há uma repetição das mesmas páginas, à exceção da "Greve Educação Estadual RJ", que se destaca apenas no segundo critério (perfis mais compartilhados).

Para esse trabalho, excluímos os perfis "Jornalistas Livres" e "Mídia Ninja" da análise, por serem veículos da mídia não tradicional brasileira, uma mídia ativista, mas que ainda assim não representa páginas "criadas por ocupações". O próprio fato das três páginas mais seguidas e compartilhadas serem a "Não fechem minha escola", "O mal educado" e "Escolas do RJ em Luta" já nos mostra que os secundaristas optaram por controlar sua narrativa e a produção de saberes sobre o movimento a partir do ponto de vista daqueles que o realizam. Acrescentámos a essas três fan pages a página da ocupação "Ocupa Padre Réus", para acrescentarmos manifestações identitárias em seu caráter mais específico de expressão de uma escola única e não apenas de páginas que funcionam como centrais de informações para diversas outras ocupações (o caso das três primeiras).

Em nossa análise levamos em conta "a perspectiva de metodologia como o acompanhamento refletido daquilo que se está fazendo", onde se encontra "no seu próprio desenvolvimento as pistas para seu controle metodológico" (Braga, 2011, p. 9) ${ }^{18}$. Buscamos inspiração na cartografia, enquanto pensamento deleuziano e guattariano que surge como um dos princípios do rizoma'9 ${ }^{19}$ (Deleuze \& Guattari, 1995). Deleuze e Guattari sinalizam que a cartografia não é, para eles, uma doutrina científica e nem a tomamos aqui como tal. Seguimos a inspiração cartográfica como lente de leitura para dedicarmo-nos ao nosso objeto. Para operacionalizar o tratamento dos enunciados encontrados, nos valemos também de Kastrup (2009) que, ao compreender a cartografia a partir de Deleuze e Guattari, a entende "como um método (...) que visa a acompanhar um processo e não representar um objeto" (Kastrup, 2009, p. 32), definindo pistas do trabalho cartográfico. São elas: a observação panorâmica, a observação concentrada, o pouso e o zoom sobre o objeto, a necessidade de recortes e, por fim, a composição de mapas através do reconhecimento atento, do tratamento do discurso enquanto acontecimento e da conexão de regularidades (Kastrup, 2009). Nosso objetivo é observar as expressões identitárias que estão sendo postas em circulação pelos ocupantes secundaristas pela perspectiva da possibilidade de criação de paisagens, de conexão de múltiplos fragmentos justamente em seu caráter de multiplicidade e de conexão.

\footnotetext{
${ }^{15}$ Retirado de http://www.labic.net/labic/

${ }^{16}$ Esta página pode ser consultada em https://www.facebook.com/naofechemminhaescola/

${ }^{17}$ Retirado de http://www.labic.net/labic/

${ }^{18}$ Retirado de http://compos.org.br/seer/index.php/e-compos/article/viewFile/665/503

19 "O rizoma se refere a um mapa que deve ser produzido, construído, sempre desmontável, conectável, reversível, modificável, com múltiplas entradas e saídas, com suas linhas de fuga" (Deleuze \& Guattari, 1995, p. 33). O rizoma, em Deleuze e Guattari, não possui sistemas centrados, comunicação hierárquica ou ligações preestabelecidas: é movimento a-centrado, sem núcleo organizador, sem início, nem conclusão.
} 


\section{OS PERFIS DO “OCUPA ESCOLA"}

Nas suas páginas, os alunos escrevem seus manifestos, mostram através de texto, fotografia e vídeos como estão ocupando as escolas, suas manutenções nos prédios, quadras, salas de aula; a organização de oficinas, palestras, rodas de conversas e workshops para os estudantes, pedem doações de alimentos, roupas de cama, itens de limpeza para os ocupantes, publicam convites a eventos e manifestações nas ruas. Além disso, é comum que todas essas páginas também se posicionem sobre diversos assuntos compartilhando notícias sobre o próprio movimento "Ocupa Escola", mas também sobre a situação política do país, sobre pautas relacionadas à defesa da diversidade e sobre repressão policial enfrentada por escolas ocupadas, por exemplo. Analisamos apenas posts do ano de 2016 em cada uma das quatro fan pages observadas, entendendo que o movimento possui desdobramentos diferentes em 2016 em relação a 2015 . Ao lermos os posts e separarmos aqueles que nos pareciam mais elucidativos, regularidades temáticas foram se apresentando, ao mesmo tempo em que víamos temas conectarem-se, cruzarem-se nas expressões identitárias dessas fan pages.

Ver de que forma esses estudantes estão se apresentando, realizando uma escrita de si e do seu movimento através do Facebook, nos auxilia a compreender a multiplicidade do movimento, sem que as múltiplas faces identitárias encontradas representem necessariamente uma redução do seu caráter de potência. Lembramos com Silva e colegas (2016) que "há uma singularidade em todas as qualidades antes de elas serem atualizadas em um estado de coisas e, por consequência, individuadas" e que "não se pode isolar a singularidade e a identidade de seu efeito na cadeia sígnica" (Silva et al., 2016, p. 186). Como, então, as singularidades presentes em uma multidão política, ativista, se individuam nas referências ao objeto do "Ocupa Escola"? Em nossa análise, de caráter qualitativo, identificamos grupos, constelações de temáticas mais recorrentes, que se avizinham, se conectam, jamais estão isoladas. Por questões de limitação de espaço, iremos abordar neste artigo as três constelações que nos pareceram mais significativas das expressões identitárias do movimento na sua relação com o conceito de potência da multidão.

\section{HORIZONTALIDADE, AUTONOMIA E MOVIMENTO SEM LIDERANÇA}

O conceito de horizontalidade corresponde, para Milton Santos (1996) ao acontecer homólogo e complementar nas relações cotidianas, enquanto a verticalidade se refere ao acontecer hierárquico. Para Santos (1996), uma constituição horizontal fortifica traços de união e compartilhamento entre a sociedade. A horizontalidade se liga aos processos que ocorrem no espaço cotidiano e inclui relações de solidariedade e resistência, cuja natureza pode ser econômica, social, cultural ou geográfica. Em um ambiente de horizontalidade "a sobrevivência do conjunto, não importa que os diversos agentes tenham interesses diferentes, depende desse exercício da solidariedade, indispensável ao trabalho e que gera a visibilidade do interesse comum" (Santos, 2000, p. 53) 20.

\footnotetext{
${ }^{20}$ Tal reflexão sobre o conceito de horizontalidade foi realizada anteriormente em uma análise, do ponto de vista da semiótica da cultura, dos códigos de horizontalidade nas ocupações do Rio Grande do Sul, Brasil, e pode ser encontrada em Rosário et al., 2016.
} 
Nas fan pages analisadas, o tema da horizontalidade aparece em posts, em falas dos ocupas em entrevistas fornecidas a veículos de mídia e compartilhadas, em vídeos que viralizaram no Brasil, em manifestações diversas.

A ocupação é um movimento em que nos sentimos parte da escola, é um espaço democrático em que todos têm voz, diferente do que costuma ser a própria escola. A ocupação nos garante um espaço sem opressão e que seja emancipador. Por isso, quando ocupamos, ocupamos com nossas pautas de reivindicações mas também ocupamos para mudar a maneira vertical como se decidem as coisas. Ninguém nunca nos pergunta nada sobre a escola. Não somos importantes? Não temos direitos? A ocupação nos mostrou que temos ${ }^{21}$. (grifos nossos)

Ao referirem-se a um espaço democrático onde todos têm voz, as ocupações nos transferem mais uma vez para a multidão, para um corpo não unificado, mas um conjunto de singularidades que age, um "ator social ativo", dispositivo de "democracia absoluta" em que a autonomia imanente vai dando conta da vontade geral (Negri, 2003; Silva et al., 2016). Mas, ao mesmo tempo em que desejam superar a "maneira vertical como se decidem as coisas", as ocupações também reconhecem em seus perfis que necessitam de apoio, contanto que esses não se sobreponham aos desejos dos ocupas. É que a "multidão precisa de um projeto político para passar a existir" (Negri, 2004, p. 40).

Que os secundaristas ocupados ganhem sua própria autonomia, não se deixando aparelhar pelos estudantes universitários (principalmente). Sem autonomia, o risco é tudo virar um "odara" pós-moderno. É importante a solidariedade dos movimentos sociais para engrossar a luta dos ocupados. Contudo, o mais importante é que as deliberações coletivas pertençam às dinâmicas próprias desses atores que lutam contra a reforma do ensino médio e a PEC 241. Caso contrário, a ocupação vai virar fetiche tautológico ${ }^{22}$. (grifos nossos)

Os secundaristas se afirmam autônomos e auto-governados. Seu procedimento é organizacional e político: deliberam por assembleias, buscam praticar redes horizontais na internet e nos espaços ocupados e desafiam a ordem vertical. Vemos os secundaristas incorporando em suas expressões no Facebook os códigos de uma nova concepção de movimento social, ao mesmo passo em que rechaçam e esforçam-se em seu discurso em distanciar-se dos movimentos partidários tradicionais marcados mais fortemente por uma verticalidade em sua organização:

sem aparelhamento partidário, o desafio de construir uma frente forte era preocupante, porém, o estudante secundarista mostrou sua força, seu empenho e vontade de vencer essa luta: construímos um ato que reuniu

\footnotetext{
${ }^{21}$ Retirado de https://www.facebook.com/EscolasR/emLuta/?fref=ts

${ }^{22}$ Retirado de https://www.facebook.com/mal.educado.sp/?fref=ts
} 
milhares de estudantes e simpatizantes da causa, levando as Entidades ao desespero ao ver a sua hierarquia em relação aos estudantes desaparecendo ${ }^{23}$. (grifos nossos)

Mais um exemplo: "quando limpamos as salas, foi triste vê-las hierarquicamente organizadas novamente. Lamentável"24. Aqui, vemos como estratégias identitárias de desindentificação, de uma desincorporação de lideranças e de associação à instituições vai aparecendo. Assim como não há unificação nas pautas e reivindicações, também não há nas lideranças e há um esforço em reforçar discursivamente isso.

"O movimento é de todos. Se não estivermos todos juntos, não conseguiremos nada", esclareceu Ana Júlia, 16 anos, reforçando o tempo todo que $o$ movimento das ocupações é feito por todos os alunos - por isso pediu para que a foto desta reportagem fosse feita com os colegas, e não sozinha ${ }^{25}$.

Enquanto se desindentifica em relação a instituições, entidades estudantis, partidos políticos e formas convencionais de liderança, as manifestações das ocupações também vão aproximando o movimento da ideia de multidão enquanto potência de expressão e cooperação (Negri, 2004), sem que essa desincorporação dos líderes represente um problema para o seu projeto político. É o caso da fala da estudante Ana Júlia Ribeiro, em vídeo que viralizou entre os estudantes das ocupações: "nossa única bandeira é a educação. Nós somos um movimento apartidário. Somos um movimento de estudantes pelos estudantes. Somos um movimento que se preocupa com o futuro" (Ribeiro, 2016).

Acreditamos que, ao negarem a verticalidade e lideranças, mesmo internas aos ocupas, o "Ocupa Escola" opta por uma estratégia identitária de resistência, uma vez que subverte a lógica vigente, exercita a autonomia e auto-organização onde antes havia disciplina e obediência e insiste na lógica da partilha do comum, acolhendo a ausência de unidade. Enquanto "os que acusam conceito de multidão enxergam-no como uma nova identidade que busca dominar as outras" (Negri, 2004, p. 42), as ocupações com suas múltiplas vozes em ação, múltiplas reivindicações e faces, e celebração da união, deliberação e colaboração coletiva entre estudantes rompe a alternativa numérica entre singular e plural. É multidão e "não multidões", porque "multidão" não enfatiza para nós alguma unidade, e sim a capacidade social e política comum da multidão" (Negri, 2004, p. 42).

\section{Abertura À Diversidade}

Uma das críticas que o pensamento da multidão faz é que, na modernidade, abstraiu-se a identidade das singularidades unificando a identidade em conceitos como povo, nação, raça, indivíduo (Negri, 2004; Silva et al., 2016) A multidão, ao contrário

\footnotetext{
${ }^{23}$ Retirado de https://www.facebook.com/EscolasR/emLuta/?fref=ts

${ }^{24}$ Retirado de https://www.facebook.com/ocupa.padreco/

${ }_{25}$ Ana Júlia Ribeiro, secundarista em entrevista a Rossi, El País Brasil, 2016. Retirado de http://brasil.elpais.com/brasil/2016/10/28/politica/1477657388_783213.html
} 
do povo, que é uno, é múltipla e assume as inúmeras diferenças internas que não serão jamais reduzidas a uma unidade ou identidade única. Deste modo, "diferentes culturas, raças, etnias, gêneros e orientações sexuais; diferentes formas de trabalho; diferentes maneiras de viver; diferentes visões de mundo; e diferentes desejos. A multidão é uma multiplicidade de todas essas diferenças singulares" (Hardt \& Negri, 2005, p.12).

E não nos basta que a educação seja pública e gratuita (...) Queremos que as escolas não só ensinem o necessário para o vestibular, mas que a escola forme pessoas que transformarão o mundo. Queremos que nossos professores tenham liberdade para nos ensinar política, gênero e sexualidade. (...) Queremos que a educação cumpra seu papel libertador e promova mudanças na estrutura de cada um de nós e da sociedade. Por isso ocupamos. Porque queremos mudanças ${ }^{26}$.

Ao lermos as publicações dos estudantes e irmos conectando as constelações temáticas que surgem nesse artigo, uma profunda ligação com a pauta de abertura e respeito à diversidade e, mais que isso, de exigência de que esse pensamento passe a fazer parte do cotidiano escolar se apresentou como uma das linhas de força mais presente nesse panorama das expressões identitárias do "Ocupa Escola". O primeiro enunciado que chamou a atenção foi a grande quantidade de oficinas, rodas de conversa e workshops realizados nas escolas ocupadas com temáticas como feminismo, respeito à comunidade transsexual, racismos, violência contra a mulher e como essas se repetiam em diferentes localidades. Além disso, a própria forma de expressão dos secundaristas, de incluir comunidades não cisgêneros em seus textos, de muitas vezes adotar a eliminação dos artigos que indicam gênero sexual ligado ao feminino ou masculino (usando, por exemplo, "todEx", tod@s"), assim como o tipo de matérias compartilhadas ia nos dando indicações de como se constitui nessa grande pauta temática da diversidade um movimento de identificações estratégicas.

É claro que podemos lembrar que o movimento "Ocupa Escola" é realizado e enunciado em seus perfis principalmente por estudantes do Ensino Médio, ainda jovens em idade e em experiência acadêmica - nem todas as perspectivas sobre a diversidade são abordadas, em sua complexidade teórica, filosófica, social. Ainda assim, soa impactante ver como os seus perfis não se opõem somente às más condições da educação no país, ao governo, partidos políticos, à verticalidade de instituições políticas tradicionais, mas também ao que Preciado (2011, p. 18) ${ }^{27}$ chama de "epistemologias sexopolíticas straight" e outras formas de manutenção de privilégio dominante. No discurso de Ana Júlia, vídeo já mencionado, pode-se vê-la dizer, por exemplo: "escola sem partido é uma afronta. É uma escola sem senso crítico. É uma escola racista. É uma escola homofóbica. (...) Em pleno ano de 2016 , vocês querem nos colocar um projeto desses?" (Ribeiro, 2016). Ao aproximar-se de diferentes identidades coletivas - estrategicamente escolhidas -, os

\footnotetext{
${ }^{26}$ Retirado de https://www.facebook.com/ocupa.padreco/

${ }^{27}$ Retirado de https://periodicos.ufsc.br/index.php/ref/article/view/So104-026X2011000100002/18390
} 
secundaristas expressam-se enquanto grupo intrinsicamente conectado à aceitação e produção de diferença, condição essencial para pensarmos em singularidades da multidão individuando-se ainda dentro da lógica da multiplicidade.

Diferentes formas de aulas. Debate de gênero e sexualidade? Teve sim! Pois somos a geração da inclusão! Debate sobre feminismo? Teve sim! Pois a organização das excelentes alunas é lindo! Mulheres de luta! Debate sobre racismo? Teve sim! Pois racistas opressores não passarãa! ${ }^{28}$ (grifo dos autores)

Assim, compreendemos que há singularidades do movimento que estão, a partir das transformações, movimentos, semioses que o "Ocupa Escola" vivencia, flutuando em relação a expressões identitárias difusas e múltiplas, ao mesmo tempo que permitem perceber uma certa desindentificação necessária à existência das multidões, como nos aponta Preciado (2011).

Do mesmo modo, quando vemos a legitimidade, atualidade e relevância das causas identitárias pelas quais o "Ocupa Escola" optou reivindicar, além de uma estratégia de aderência popular, já que seus posts com essas temáticas geram compartilhamentos, comentários positivos, talvez seja possível vislumbrar vetores de singularidade e da multiplicidade que contornam o movimento, da potência do múltiplo que permanece imanente. $\mathrm{O}$ espírito do comum mais uma vez está presente, um comum que se realiza pelo respeito à diferença, diferenças que compartilham um terreno comum de ação e se aproximam do radical anti-individualismo político que faz parte da multidão (Hardt \& Negri, 2005). Trazendo debates como os das questões de gênero, do machismo, da cultura do estupro, propondo as próprias oficinas e discussões, realizando vídeos e paródias com músicas populares no Brasil que falam a respeito dos seus temas de interesse, os secundaristas mostram uma luta que se expressa também de forma criativa. Os secundaristas não são o movimento estudantil, não são um movimento negro, não são um movimento feminista, um movimento trans, um movimento de trabalhadores operários: são fluxos que se atravessam e encostam suas superfícies em todos esses territórios identitários, sem unificar-se em um deles.

\section{“OCUPA EsColA" Não É BAGUNÇA: NARRATIVAS DA OCUPAÇÃo X INVASÃo}

"Ocupa não é bagunça"29

Os enunciados que mais despertaram a nossa atenção foram aqueles sobre o exercício do cuidado público dos secundaristas em relação a suas escolas ocupadas. Muitos posts voltados ao registro do cuidado com o patrimônio público, com a realização de melhorias em salas de aula, áreas externas, ginásios, convites à comunidade para se juntarem e participarem, "multirões". Fotos, vídeos das melhorias realizadas. Essa temática do cuidado público nos pareceu evidenciar algumas estratégias enunciativas em busca

\footnotetext{
${ }^{28}$ Retirado de https://www.facebook.com/ocupa.padreco/

${ }^{29}$ Retirado de https://www.facebook.com/ocupa.padreco/
} 
de legitimação e de transformação de identificações negativas (relacionadas à bagunça, baderna, desejo de não ter aulas, por exemplo) em possíveis e desejáveis lugares de potência.

Ocupamos porque lutamos por uma educação pública e de qualidade, mesmo que muitos insistam em dizer que é porque somos vagabundos, massa de manobra, etc. Aliás, por que, até mesmo quando a juventude decide tomar a política em suas mãos, ainda insistem em nos taxar de fúteis e desocupados? 30

As ocupações são verdadeiras aulas públicas de construção coletiva. Na ocupação temos que organizar nossa alimentação, segurança, comunicação e cuidar de toda nossa escola. (...) Organizamos oficinas com temáticas que geralmente não temos no nosso cotidiano escolar, mas que existiriam se a escola tivesse a nossa cara $^{31}$. (grifo nosso)

Em publicações como essas, e em outras como "nós não estamos lá pra fazer baderna. Nós não estamos brincando. Nós, estudantes que estamos na escola, não somos vagabundos" (Ribeiro, 2016), vemos o esforço dos secundaristas em subverter a ideia de ocupação ligada à invasão, de manifestantes enquanto "desocupados", "vagabundos", "bagunceiros", "fúteis". Quando pensamos com Bentes (2016) que as ocupações (de diferentes tipos) podem ser entendidas como dispositivo político que emerge de disputas simbólicas nos campos do espaço público, do imaginário e da linguagem, nessa constelação do cuidado público e da reafirmação de que "ocupa não é bagunça" estamos vendo uma luta simbólica no sentido da desterritorialização dos sentidos negativos associados ao movimento.

$\mathrm{Na}$ busca por reverberar aquilo que compõe a experiência das ocupações, esforçam-se também em construir mais uma vez adesão pública e, especialmente nessas publicações, em desterritorializar velhos conceitos ligados a manifestantes ou ao movimento estudantil, ou simplesmente ao fato de serem adolescentes compartilhando o ambiente da escola; tentam, assim, ganhar apoio da comunidade em geral, e despojar suas vinculações identitárias a estigmas e representações equivocadas.

No Brasil, tal estratégia narrativa mostrou-se bem sucedida enquanto fórmula para chamar a atenção para as ocupações, despertar solidariedade de voluntários e de atrair personalidades públicas brasileiras que passaram a participar de eventos e ações nas escolas, em sinal de apoio a essa tática do cuidado público. Artistas fizeram shows, chefs famosos participantes de reality shows culinários foram às escolas para cozinhar merenda, e cada ação desse tipo representava muitas vezes viralização, inúmeros compartilhamentos e mais foco para o "Ocupa Escola". Percebe-se, assim, os perfis do "Ocupa Escola" produzindo expressões que tentam movimentar lógicas

\footnotetext{
${ }^{30}$ Retirado de https://www.facebook.com/EscolasR/emLuta/?fref=ts

${ }^{31}$ Retirado de https://www.facebook.com/EscolasRJemLuta/?fref=ts
} 
antigas, comunicar novos territórios e reelaborar as identificações e a legitimação desse movimento social.

\section{CONSIDERAÇões}

O movimento Occupy das escolas brasileiras participa de uma nova forma de distribuição no espaço já adotada por outros movimentos com forte ligação com a lógica da sociedade em rede: uma mistura de espaços físicos e territóriais com espaços de fluxos, na internet. Do ponto de vista comunicacional, este fluxo não apenas traz grande valor informativo e criativo, como também aponta para uma nova onda mais complexa e aberta ao dissenso: em um rastreio pelas inúmeras páginas de Facebook que foram criadas pelas escolas ocupadas, encontramos formas muito distintas de comunicar, assim como objectivos que diferem de uma escola para outra, sem homogeneidade de intenções desde o princípio desse movimento. Ao mesmo tempo, caracterizam-se por elementos com os quais Bentes (2015) descreve a mídia-multidão: a da produção de comunicação por afectação e das próprias irregularidades e desafios que se apresentam para produzir narrativas plurais, uma vez que até certo ponto, o activismo não admite essa alternância de perspectivas quando fica prisioneiro de um discurso de verdade.

Nesse ponto, vimos em nossa incursão pelas páginas do Facebook do movimento um amplo espaço de multiplicidade, sem horizontes de unidade ou de totalização. Uma constelação de enunciados identitários menos próximos de uma identidade robusta, totalizante, e mais associados à ideia do encontro tão caro à multiplicidade, a uma lógica em que as imanências ali presentes criam a potência necessária para aumentar coletivamente a potência conjunta. Entre as regularidades percebidas na análise, se apresentaram com mais intensidades pautas como a educação de qualidade com senso crítico; as críticas a repressão policial em relação ao movimento; a resistência contra um governo ilegítimo e, com mais luminosidade e, por isso, objeto de atenção específica neste artigo, os temas da horizontalidade, autonomia e de um movimento sem liderança; a abertura à diversidade e a insistente necessidade em reafirmar o cuidado público com a escola. Nessa composição, não há categorias isoladas. As temáticas se articulam, se conectam e os procedimentos estratégicos de expressão identitária do movimento não operam nunca isolados. A análise nos permitiu destacar alguns desses procedimentos, tais como a busca por adesão popular; o apoio a identificações estratégicas com o perfil, desejos e posicionamento ético-político do movimento; a aproximação com diferentes identidades coletivas; o uso dos perfis no Facebook para manifestar identidades de resistência; e os esforços em torno de transformar identidades negativas e estereotipadas - da ocupação enquanto invasão, do movimento estudantil, dos estudantes adolescentes - em lugares de transformação e potência.

Nas manifestações do "Ocupa Escola", vimos traços de reivindicação, desterritorialização de sentidos sobre a escola e a postura dos alunos, ativismo e potência. Seguimos acreditando na produtividade de analisar movimentos como esse da perspectiva das ações políticas, sociais, culturais das multidões. Os enunciados dos perfis do 
Facebook do "Ocupa Escola" analisados neste trabalho indicam pistas de como velhos estatutos da identidade de movimentos sociais podem ser repensados e de como do encontro de singularidades desejantes se produzem acontecimentos, se organiza uma linguagem comum, "uma linguagem que nasce da indignação e do protesto, do cansaço de sempre se encontrar em situações que não têm saída" (Negri, 2014, s.p.) ${ }^{32}$. Ainda que diferentes agenciamentos identitários possam ser identificados entre os secundaristas, talvez o retorno a essa conexão entre identidades e singularidades seja uma problematização necessária para as exigências do nosso tempo: "a multidão se organiza à base de paixões que caminham junto com a resistência; quando a multidão se move, nunca é simplesmente massa, é uma riqueza plural de elementos de vida" (Negri, 2014, s.p.).

\section{REFERÊNCIAS BIBLIOGRÁFICAS}

Alim, S. (2012a). A palavra do ano é "Occupy". Revista Fórum. Retirado de http://www.revistaforum.com. $\mathrm{br} / 2012 / 01 / 01 / a-p a l a v r a-d o-a n o-e-o c c u p y /$

Alim, S. (2012b). What if we occupied language? The New York Times. Retirado de http://opinionator.blogs. nytimes.com/2011/12/21/what-if-we-occupied-language/?_r=0

Braga, J. L. (2011). A prática da pesquisa em Comunicação: abordagem metodológica como tomada de decisões. Revista E-compós, 14(1), 1-33. Retirado de http://compos.org.br/seer/index.php/e-compos/ article/viewFile/665/503

Bentes, I. (2015). Mídia-Multidão: estéticas da comunicação e biopolíticas. Rio de Janeiro: Mauad X.

Bentes, I. (2016). A última maçã no paraíso. Revista Cult. Retirado de http://revistacult.uol.com.br/ home/2016/10/a-ultima-maca-do-paraiso/

Guatarri, F. \& Rolnik, S. (2011). Micropolítica: cartografias do desejo. Petrópolis, RJ: Vozes.

Hardt, M. \& Negri, A. (2005). Multidão: guerra e democracia na era do Império. Rio de Janeiro: Record.

Kastrup, V. (2009). O funcionamento da atenção no trabalho do cartógrafo. In E. Passos, V. Kastrup, E. \& L. Escóssia, Pistas do método da cartografia: pesquisa-intervenção e produção de subjetividade (pp. 32-51). Porto Alegre: Sulina.

Negri, A. (2003). Cinco lições sobre Império. Rio de Janeiro: DP\&A.

Negri, A. (2002). O poder constituinte: ensaio sobre as alternativas da modernidade. Rio de Janeiro: DP\&A.

Negri, A. (2004). Para uma definição ontológica da Multidão. Lugar Comum, 19-20, 15-26.

Perissé, G. (2011). Quem ocupa se preocupa? Blogue Palavras e Origens. Retirado de http://palavraseorigens. blogspot.pt/2011/11/quem-ocupa-se-preocupa.html

Preciado, B. (2011). Multidões queer: para uma política dos "anormais". Revista Estudos Feministas, 19(1), 11-20. Retirado de https://periodicos.ufsc.br/index.php/ref/article/view/ So104-026X2011000100002/18390.

${ }^{32}$ Retirado de http://zh.clicrbs.com.br/rs/noticias/proa/noticia/2014/o6/antonio-negri-e-a-multidao-que-comanda-a-historia-4520222.html 
Ribeiro. A. J. (2016). Discurso na Assembléia Legislativa do Paraná. Retirado de https://www.youtube.com/ watch?v=pUQLs9y_fx4

Rosário, N. M., Silva, C. \& Miranda, D. (2016). Ocupações dos secundaristas do RS: tensões culturais e reconfigurações comunicativas. Revista Intexto, 37, 193-214. Retirado de http://seer.ufrgs.br/index.php/ intexto/article/view/67924/39623

Silva, A.; Nonino, G. \& Macedo, L. (2016). Uma leitura semiótica das multidões. Revista Intexto, 37, $176-192$. Retirado de http://seer.ufrgs.br/index.php/intexto/article/view/66964/39613

\section{OUTRAS REFER̂̂NCIAS}

American Dialect Society (2012). "Occupy" is the 2011 Word of the Year. Retirado de http://www. americandialect.org/occupy-is-the-2011-word-of-the-year

Escolas do RJ em luta [perfil do Facebook]. Retirado de https://www.facebook.com/EscolasRJemLuta/?fref=ts

Mal educado [perfil do Facebook]. Retirado de https://www.facebook.com/mal.educado.sp/?fref=ts

Malini, F. (2016). A multiplicidade do Eu no \#OcupaEscola: como o compartilhamento de posts das páginas do movimento \#OcupaEscola indica o arco de aliança que os secundaristas estão a construir. Retirado de https://medium.com/@fabiomalini/o-ecossistema-sócio-midiático-do-ocupatudo-cf589a0781af\#. bfovoibi7

Negri, A. (2014). É a multidão que comanda a história. Retirado de http://zh.clicrbs.com.br/rs/noticias/proa/ noticia/2014/06/antonio-negri-e-a-multidao-que-comanda-a-historia-4520222.html.

Ocupa Padre Réus [perfil do Facebook]. Retirado de https://www.facebook.com/ocupa.padreco/

Ribeiro. A. J. (2016). Discurso na Assembléia Legislativa do Paraná. Retirado de https://www.youtube.com/ watch?v=pUQLs9y_fx4.

Rossi, M. (2016). Ana Júlia Ribeiro, a estudante que discursou na Assembleia: "PEC 241 é uma afronta". Retirado de http://brasil.elpais.com/brasil/2016/10/28/politica/1477657388_783213.html.

Torturra, B. (2016). Entmagazine com Fábio Malini. Córtex - mapas de rede, trends de rua e a política na era do perfil: um passeio com Fábio Malini [vídeo]. Produtora Fluxo: São Paulo (7ımin). Retirado de http://www.labic.net/cartografia/ cortex-mapas-de-rede-trends-de-rua-e-a-politica-na-era-do-perfil-um-passeio-com-fabio-malini/

\section{NOTA BIOGRÁFICA}

Danielle Miranda é mestre em Comunicacão e Informação pela Universidade Federal do Rio Grande do Sul, Brasil, e atualmente estuda Cultura Contemporânea e Novas Tecnologias no mestrado em Ciências da Comunicacão da Universidade Nova de Lisboa.

E-mail: danimiranda.andrigo@gmail.com

Morada: Travessa Gaspar Trigo, 22, R/C, 1150-169, Lisboa, Portugal

* Submetido: 30-05-2017

* Aceite: 17-07-2017 